\title{
Homeo Domain
}

National Cancer Institute

\section{Source}

National Cancer Institute. Homeo Domain. NCI Thesaurus. Code C13367.

The DNA-binding homeo domain was originally identified in transcription factor proteins encoded by homeobox genes (homeotic genes). The homeo domain is structurally similar to the helix-turn-helix DNA-binding domain of CRO and Lambda repressor. 